\title{
Occupational genital injuries during 10 years in pistachio farmers, Rafsanjan, Iran
}

\author{
Abedinzadeh $\mathrm{M}, \mathrm{MD}^{1 *}$, Vaseghi $\mathrm{H}^{2}$, Abedinzadeh $\mathrm{M}^{3}$ \\ 1- Assistant Prof., Dept. of urology, Moradi hospital, Rafsanjan University of Medical Sciences, Rafsanjan, Iran. 2. \\ Medical Student, Tehran University of Medical Sciences, Tehran, Iran. 3- Student, Javadolaemeh High School, Yazd, \\ Iran
}

Abstract:

Received: September 2011, Accepted: October 2011

Background: Genital injuries are important because of their association with injuries to major organs and vasculature of pelvis. Both degolving of genitalia skin and amputation of penile glans and testis are rare conditions. Although genital injury is rarely life threatening, it can result in serious sexual, psychological and physiological consequences. This study aimed to introduce few very rare cases with genital injuries among pistachio farmers in Rafsanjan, Iran.

Materials and Methods: This study is a case series conducted from 2000 up to 2009 in Moradi hospital of Rafsanjan city, Iran. Patients' data were gathered during 10 years and analyzed using SPSS software version 16.

Results: Among 9 victims of genital injuries, caused by accident with tractor during spraying pistachio farms, 7 had suffered from partial or total scrotal or penile degolving, one suffered from testis amputation and one from penile glans amputation. Mean age of victims was $28.6 \pm 3.57$ years, and they were unemployed for $3.1 \pm 0.78$ weeks on average.

Conclusion: In order to reduce genitalia injuries caused by agricultural machinery, tractors safety should be given more attention and also pistachio farm workers should become aware of these occupational risks.

Key words: Genital, Genitourinary, Occupational injuries, Trauma, Pistachio farms, Rafsanjan

\section{Introduction}

Genital injuries are important because of their association with injuries to major organs and vasculature of pelvis [1]. Avulsions or degloving injuries of the penile and scrotal skin are rare urology emergencies [2]. They mainly occur due to accidents by industrial machines and agricultural machine belts in which the clothing of the perineal region is entangled in a rotating machine. Avulsions may vary from simple lacerations to total emasculations [2, 3]. Generally, lesions do not damage the cavernous body, the spongy body or the testes; they only reach the skin, causing minimal bleeding.
The overlying skin of the penis is loose, elastic and highly mobile which predisposes the skin to be ripped off easily from the penis and cause avulsion injuries [2]. Amputation of the penile glans is a rare condition. It has been reported from various parts of the world as isolated cases or small series of patients. The most common etiology is self-mutilating sharp amputation [4]. Furthermore, penile amputation and emasculation secondary to injuries caused by

\footnotetext{
corresponding to: Mehdi Abedinzadeh, Dept. of urology, Moradi hospital, Rafsanjan university of medical sciences, Rafsanjan, Iran.

Email: abedinoro@yahoo.com
} 
modern machinery is extremely uncommon [2].

Although genitourinary trauma is rarely life threatening, it can result in serious psychological and physiological consequences. Also, such lesions are incapacitating $[2,3]$ and may be the cause of significant long-term morbidity [5]. Because of unpleasant sexual, psychological and physiological consequences of genital injuries and to make associated organizations and people aware of these unpleasant events happening during working in farms, and in order to prevent more injuries, 9 very rare cases of genital injuries caused by rotating axle wheel of tractor during 10 years are reported in this study.

\section{Materials and Methods}

This study is a case series conducted since the years 2000 to 2009 in Moradi hospital of Rafsanjan city. Moradi hospital has an urology center, and there are no other urology centers in this city or cities around, so all of urological patients of the city must ultimately come to this hospital.

As patients referred to the hospital in the emergency ward, they were examined and evaluated to see how much damage had occurred. Their blood pressures (BP) and blood hemoglobin (HB) amounts were measured in order to estimate how much normal saline or blood they needed. Their genital areas were washed with normal saline, bandaged with Vaseline gauze, intra venous (IV) ceftriaxone $(1 \mathrm{gr} / 12 \mathrm{~h})$ was given to them, and also normal saline IV or blood was administered if needed when the patient was hemodynamically stabled. Then the patients were sent to the surgery room. Information about type of the trauma, time of the accident, duration of their hospitalization and employment status, their
$\mathrm{BP}$ and blood $\mathrm{Hb}$ as they came to the hospital, age, admission date, normal saline and blood administration and causes of the accident were recorded on the study checklist by a trained expert. Then the data were analyzed using SPSS software. For description of continuous variables, mean and standard deviation (SD) were reported. The study was conducted in accordance with the principles laid down in the Declaration of Helsinki, Written informed consent was obtained from all the patients. Ethical approval was also taken from the ethics committee of Rafsanjan University of Medical Sciences.

\section{Results}

During the past 10 years, from 2000 to 2009 , nine genital injuries had occurred. Accidents with rotating axel wheel of tractor during spraying pistachio plants in May or June was the cause of all of these traumas. Three patients needed normal saline administration and two of them received both normal saline and blood, considering their $\mathrm{BP}$ and $\mathrm{HB}$. Intra venous (IV) ceftriaxone ( $1 \mathrm{gr} / 12 \mathrm{~h})$ was given to all of the patients in order to prevent infection.

Patients ranged from 25 to 35 years old, with the mean of $28.6 \pm 3.57$ ) years. Mean of their hospitalization days was $5.2 \pm 1.56$, (37 days) days and they were unemployed for $3.1 \pm 0.78$, (2- 4weeks) weeks on average. Two patients were taken to the hospital at night, whereas, six were taken at noon and one in the morning. Seven patients suffered from partial or total penile or scrotal degolving, one from amputation of a testis and degolving scrotal skin of the same side and one from partial penile cutting including glans. Important factors that were measured for each person such as type of trauma, their age, date of administration, their BP and HB 
as they came to the hospital, normal saline or blood administration, hospitalization days and unemployment weeks are presented in table 1 .

Table1: Some characteristics of genital injured pistachio farmers during 2000-2009

\begin{tabular}{|c|c|c|c|c|c|c|c|c|}
\hline \multirow[b]{2}{*}{$\begin{array}{l}\text { The severity of resulting } \\
\text { injuring }\end{array}$} & \multicolumn{8}{|c|}{ Patients characteristics } \\
\hline & Age & date & BP & HB & $\begin{array}{l}\text { Normal } \\
\text { saline A }\end{array}$ & $\begin{array}{c}\text { Blood } \\
\text { A }\end{array}$ & $\begin{array}{c}\mathrm{H} \\
\text { days }\end{array}$ & $\begin{array}{c}\text { Unemplo } \\
\text { yment } \\
\text { weeks }\end{array}$ \\
\hline \multicolumn{9}{|l|}{ - total penile skin } \\
\hline degolving & 25 & May 2000 & $\mathrm{~N}$ & $\mathrm{~N}$ & No & No & 5 & 3 \\
\hline - total penile and scrotal & & & & & & & & \\
\hline skin degolving & 33 & May 2001 & $\mathrm{~L}: 8.5$ & $\mathrm{~N}$ & Yes & No & 7 & 4 \\
\hline \multicolumn{9}{|l|}{ - amputation of one testis } \\
\hline \multicolumn{9}{|l|}{ and degolving scrotal skin } \\
\hline of the same side & 28 & June 2001 & $\mathrm{~L}: 8$ & $\mathrm{~L}: 8.5$ & Yes & 1 unit & 7 & 4 \\
\hline \multicolumn{9}{|l|}{ - partial penile cutting } \\
\hline including glans & 26 & June 2003 & $\mathrm{~L}: 7.5$ & $\mathrm{~L}: 9.5$ & Yes & 1unit & 7 & 4 \\
\hline \multicolumn{9}{|l|}{ - partial degolving of } \\
\hline penile skin & 35 & May 2005 & $\mathrm{~N}$ & $\mathrm{~N}$ & No & No & 3 & 2 \\
\hline \multicolumn{9}{|l|}{ - total penile and scrotal } \\
\hline skin degolving & 28 & June 2005 & $\mathrm{~L}: 8.5$ & $\mathrm{~N}$ & Yes & No & 5 & 3 \\
\hline \multicolumn{9}{|l|}{ - total degolving of penile } \\
\hline skin & 31 & June 2006 & $\mathrm{~N}$ & $\mathrm{~N}$ & No & No & 5 & 3 \\
\hline \multicolumn{9}{|l|}{ - penile and scrotal skin } \\
\hline degolving & 27 & May 2007 & $\mathrm{~L}: 8$ & $\mathrm{~N}$ & Yes & No & 5 & 3 \\
\hline - partial degolving of & & & & & & & 3 & 2 \\
\hline penile skin & 25 & June 2009 & $\mathrm{~N}$ & $\mathrm{~N}$ & No & No & & \\
\hline
\end{tabular}

$\mathrm{H}$ : hospitalization, A: administration, N: normal, L: low.

\section{Discussion}

This study reported 9 cases of scrotum skin degolvitation and penile glans and testis amputation during 10 years in Rafsanjan city. Accidents by rotating axle wheel of tractor were the cause of these injuries. In these accidents clothing is twisted and stripped off, which pulls out the loose elastic skin and other parts of genitalia. Damages vary from partial degolving to amputation of one testis. As genital skin is not tightly attached to the areas underneat, most of these injuries only involve the skin [6]. These injuries have numerous unpleasant consequences such as urinary or sexual dysfunction and serious physiological

and psychological consequences [3, 7].Four articles which were somewhat similar to our research were found. Luiz \& et al reported a case of genital injury due to industrial machinery accident [8]. Dogra PN. et al reported a case of penile amputation and emasculation secondary to crushing injury 
inflicted by agricultural machinery in their study [9].

Hodonou RK. et al reported 20 cases of external genitalia trauma with various causes during 10 years [10]. Wang DL, et all reported 2 cases of a 20 and a 29 year old (two penoscrotal avulsion victims) that were injured by agricultural machines [3]. We also found genital injuries due to accidents during working with machines similar to that of the above studies which show the frequency of this event in the other parts of the world as well. This study reported 9 cases, three different types of genitalia injuries, and was focused on agricultural machines' injuries which show the importance of caring about this issue.

The mean age of victims was $28.6 \pm 3.57$ years ( $25-35$ years) which shows that all of them were in the reproductive age and such events could cause sexual dysfunction and related psychological consequences. They were on average $3.1 \pm 0.78$ weeks, (2-4 weeks) unemployed because of their injuries which probably caused psychological and economical hardships and disorders. According to recent studies the psychological burden inflicted on male patients by this type of injuries is too great and patients may react to genital injuries with defense mechanisms such as conversation withdrawal, denial, regression, anger, anxiety, and depression [11,12].

Furthermore, avoidance of coping with problems of such traumas could be a predictor of post traumatic stress disorders (PTSD) [13].

Bleeding was severe in testis and penile glans amputation cases in which the main vessels involved required blood administration. Degolving complaint bleeding depends on the extent of involved area, but it wasn't as severe as amputation cases because only superficial vessels were involved.

\section{Conclusion}

In this study, all of the patients were working in pistachio farms. They faced these unpleasant accidents while spraying pistachio plants, which is done 3-4 times in May and June. As spraying is an essential work, tractor safety should be given more attention or they should be changed in a way to reduce these unpleasant events. Pistachio farm workers should become aware of these dangers and wear suitable clothes to avoid initiation of such events. It seems that proper educational programs are

needed to be organized for this occupational group. Further investigations are strongly suggested to work on the preventive methods as well as psychological and social consequences of this extremely important occupational accident.

\section{Acknowledgment}

We would like to thank Firoozgar Clinical Research Development Center (FCRDC) for its cooperation, and also $\mathrm{Dr}$ SeyedMohammad Fereshtehnejad, Dr Mohammad Aboohoseini Tabari and Dr Kobra Abedinzadeh who helped us with this study.

Conflict of interest: Non declared

\section{References:}

1. Wessells H, Long L. Penile and genital injuries. Urol Clin Am 2006; 33(1):117-26.

2. Mathur RK, Lahoti BK, Aggarwal G, Satsangi B. Degloving injury to the penis. Afr J Paediatr Surg 2010; 7(1):19-21.

3. Wang DL, Luo ZJ, Sun GF, Wei ZR. Longterm prognosis of free skin-grafted penoscrotal avulsion injuries in two patients. J Plast Reconstr Aesthet Surg 2009; 62(3):385-7. 
4. Gyan S, Sushma S, Maneesh S, Rajesh S, Misra M. Successful microsurgical penile replantation following self amputation in a schizophrenic patient. Indian J Urol 2010; 26(3):434-7.

5. Rosenstein D, McAninch JW. Urologic emergencies. Med Clin North Am 2004; 88(2):495-518.

6. Horton CE, Dean JA. Reconstruction of traumatically acquired defects of the phallus. World J Surg 1990; 14(6):757-62.

7. Dreitlein DA, Suner S, Basler J. Genitourinary trauma. Emerg Med Clin North Am 2001; 19(3):569-90.

8. Zanettini LA, Fachinelli A, Fonceca GP. Traumatic degloving lesion of penile and scrotal skin. Int Braz J Urol 2005; 31(3):262-3.

9. Dogra PN, Gautam G, Ansari MS. Penile amputation and emasculation: hazards of modern agricultural machinery. Int Urol Nephrol 2004; 36(3):379-80.

10. Hodonou RK, Diallo A, Akpo EC, Koura A, Hounasso PP, Goudote E. Injuries of the external male genital organs. Apropos of 20 cases. Ann Urol (Paris) 1997; 31(5):318-21.

11. Paraskevas kI, Anagnostou D, Bouris C. An extensive traumatic degloving lesion of the penis. A case report and review of the literature. Int Urol Nephrol 2003; 35(4):523-7.

12. Mohta M, Sethi AK, Tyagi A, Mohta A. Psychological care in trauma patients. Injury 2003; 34(1):17-25.

13. Tsay SL, Halstead MT, McCrone S. Predictors of coping efficacy, negative moods and posttraumatic stress syndrome following major trauma. Int J Nurs Pract 2001; 7(2):74-83. 